\title{
Benign Intracranial Neoplasm
}

National Cancer Institute

\section{Source}

National Cancer Institute. Benign Intracranial Neoplasm. NCI Thesaurus. Code C5111.

A benign neoplasm involving the intracranial area. 